\title{
The Potential of super absorbent polymers from diaper wastes to enhance water retention properties of the soil
}

\author{
Madiha Zekry, Ibrahim Nassar, Heba Salim and Ahmed Abdallah* \\ Department of Natural Resources and Agricultural Engineering, Faculty of Agriculture, Damanhour University, 59 \\ Damanhour, Egypt \\ [Received: January 06, 2020 Accepted: March 05, 2020 Published Online: March 07, 2020]
}

\section{Abstract}

The management of disposable diapers is a major problem. Moreover, light-textured soils are characterized by low water holding capacity and excessive drainage, thus significant portion of irrigation water is lost below the root zone. A laboratory study was conducted to evaluate the potential of recycling disposable baby diapers to conserve soil moisture in light-textures soils. The water absorbency [water absorption capacity (WAC) and water absorption rate (WAR)] of the recovered Super absorbent polymers (SAPS), from diapers, was evaluated and described under different ionic solute

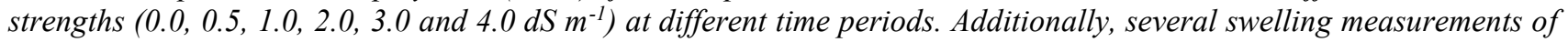
the SAPs were determined when added to sandy clay loam soil using different levels [0.0, 0.4, 0.6, 0.8 and 1.6\% (w/w)] for five rewetting cycles (over a period of 6 months). As the swelling time increased, the WAC increased, while WAR decreased. However, both WAC and WAR were reduced as the solution salinity increased. The recovered SAPs exhibited WAC of 311.0 and $111.0 \mathrm{~g} \mathrm{~g} \mathrm{~g}^{-1}$ in solution of 0.0 and $3.0 \mathrm{dS} \mathrm{m} \mathrm{m}^{-1}$, respectively. Polynomials functions were used to calculate the equilibrium time and threshold solute concentration for the SAPs. The average equilibrium time was 4.5

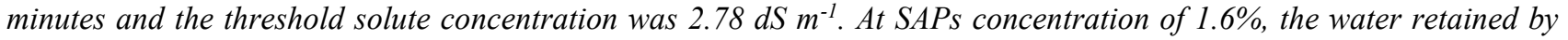
the soil increased by 2.6 folds. The specific amount of water retained (SWR) by SAPs in the SAPS-soil mixture was decreased with repeating wetting, thus, after 6 months, the average WHC of the soil was decreased by 14\% compared to initial wetting. The recycling of baby diapers might have a great potential to conserve soil moisture in light soils using water of good quality. However, since the SAPs in diapers are $\mathrm{Na}^{+}$based, further research is needed to explorer the impact of such treatment on soil chemical properties.

Keywords: Disposable diaper, polymers, water absorbency, equilibrium time, salinity threshold, absorbency rate

\section{Introduction}

The shortage of irrigation water represents a big challenge, particularly, in arid and semiarid regions (Moghbel et al., 2017; Han et al., 2018). Furthermore, sandy soils are characterized by low water holding capacity (WHC), thus a great portion of irrigation and/or rain water is lost by deep percolation, carrying nutrients away from the effective root zone (Hafeez-ur-Rahman et al., 2012) . These losses of water and nutrients result in inefficient water and nutrient use and several environmental and economic problems (Hüttermann et al., 2009). Such problems are more pronounced in plants with shallow roots (Bhardwaj et al., 2007; Abdallah 2019). Therefore, there is an urgent need for increasing the water holding capacity (WHC) of the soil, so that the water remains available in rhizosphere (Al-Jabari et al., 2019). To this aim, one of the means, is the use of hydrogels (super absorbent polymers, SAPs), which has been found to be a promising approach to increase the ability of light-textured soils to store water (Al-Jabari et al., 2019). SAPs are three-dimensional, non-water dissolved, crosslinked polymers, which are able to absorb and retain water several hundred times of their initial weight (Buchholz, 1998). SAPs' or Hydrogel's products are capable of cyclical absorption and desorption over long periods of time and so provide a slow-release- soil water reservoir (SánchezOrozco et al, 2017). When the hydrogel-amended soil starts drying, the water absorbed by hydrogel (about $80-95 \%$ of the retained water) could gradually be released to plants (Abdallah 2019; Satriani et al., 2018). Therefore, SAPs application might extend the intervals of irrigations, and provide a buffer against water stress (Han et al., 2013). However, the biggest challenge that the SAPs application in agriculture faces are the high cost, the low water absorption rate (WAR, $\mathrm{g} \mathrm{min}{ }^{-1}$ ), sustainable availability and the SAPs' sensitivity to salinity. Therefore, the main required features

\footnotetext{
*Email:ph7@damanhour.edu.eg
} 
of SAPs for agricultural use are low cost and resistance to salinity.

Most studies used commercial superabsorbent polymers (pure hydrophilic polyacrylate polymers). However, the disposable baby diaper contains a significant number of SAPs; ranging from $20 \%(\mathrm{Qu}$ and de Varennes, 2010) to $30.7 \%$ (EDANA, 2008). One gram of SAPs used in diapers retain $530.0 \mathrm{~g}$ of distilled water or $13.7 \mathrm{~g}$ of synthetic urine (Qu and de Varennes 2010). The recycling of baby diapers for obtaining SAPs might have a great potential to increase the WHC of the soil (Al-Jabari et al, 2019; Qu and de Varennes, 2010). On the other side, the generation of disposable diapers is a major problem (Sánchez-Orozco et al., 2017). Diapers are deposited in landfills, leading to severe environmental problems (Khoo et al., 2019). Therefore, the recycling of diapers is vital for environment sustainability (Espinosa-Valdemar et al., 2014). Annually, 20 billion used diapers are dumped in landfills, producing 3.5 million tons of waste (Khoo et al., 2019). Great efforts have been directed towards diapers' recycling using the anaerobic digestion (Forkes 2007), composting (EspinosaValdemar et al., 2003), and fate of the SAPs (Gerba et al., 1995). Moreover, the effect of introducing diapers in humus (Colón et al., 2010) and the biodegradability of compostable diapers have been studied (Colón et al., 2013).

In the developing countries, there is a lack of such technologies that can be applied in waste management. It has been determined that a baby can use about six diapers/day (Espinosa-Valdemar et al., 2014). Therefore, in Egypt with a population of more than 101.0 million, including about 7 million babies under the age of two years (United Nations, 2019), more than 42.0 million of diapers are used daily. Since, the average mass of a used diaper is about $210.0 \mathrm{~g}$ (Puig and González, 2009), more than 8400 tons of diaper waste are daily disposed. At present, in Egypt, used diapers are not recycled and are burned or placed in landfills. If wasted diapers are used in conserving soil moisture in light textured soils, this could represent a novel solution to mitigate the accumulation of disposable diapers. Few publications have investigated the utilization of SAPs from disposable diapers in agriculture $(\mathrm{Qu}$ and de Varennes, 2010; Sánchez-Orozco et al., 2017; Al-Jabari et al., 2019). According to the cited literature, characterization of water retention for the recovered SAPs is limited. Therefore, performance of SAPs recovered from wasted diaper was valorized to quantify the energetics of soil water retention from SAPs with five rewetting cycles (over a period of six months). The SAPs was evaluated under different levels of solution salinity as well. The objectives of this study are to address the usefulness of the use of wasted diaper SAPs as a water storage enhancement amendment in soil using water of different quality.

\section{Materials and Methods}

\section{Hydrogels recovery}

Disposable diapers were collected from local users (a private local nursery house in Damanhour, Egypt). The disposable diapers containing only urine were used. For the characterization of swelling behavior of the recovered SAPs, the diapers were first heat inactivated by autoclaving at $125.0{ }^{\circ} \mathrm{C}$ for 15.0 minutes to eliminate pathogens. After sterilizing, the diapers were chopped up and the components were separated in two parts: cellulose and plastic. The superabsorbent polymer particles intermingled with cellulose fibers were oven dried at $60.0{ }^{\circ} \mathrm{C}$ for $24.0 \mathrm{~h}$ (Sánchez-Orozco et al., 2017). The dried SAPs were retrieved by gently shaking the cellulose fibers in a plastic container in order to free the particles from the surrounding. Then, it was ground and sieved with an 80-mesh sieve. The resulting superabsorbent polymer powder (a cross-linked sodium polyacrylate) was kept in desiccators for further studies. The SAPs are a cross-linked sodium polyacrylate, it has an apparent bulk density in the range of $600-750 \mathrm{Mg} \mathrm{m}^{-}$

${ }^{3}$. It is a white powder with a typical particle size in range of $90-850 \mu \mathrm{m}$ with a majority of $90 \%$ at about $300 \mu \mathrm{m}$. For determining the effectiveness of SAPs on the water holding capacity of soil, the diapers were collected and soaked overnight in tap water $\left.0.52 \mathrm{dS} \mathrm{m}^{-1}\right)$ then the swollen SAPs were obtained and mixed with the air-dried soil.

\section{Water absorbency measurements}

To describe the swelling behavior of the recovered SAPs, two laboratory SAPs-water absorption experiments were conducted. The first lasted 60.0 minutes (to estimate the water absorption capacity) and the second 6 minutes (to estimate water absorption rate).

\section{Long equilibrium experiment (60 minutes)}

The water absorption capacity (WAC, $g$ water $\mathrm{g}^{-1}$ SAPs) of the recovered SAPs at different ionic strength were performed. The superabsorbent polymer (SAPs) was immersed in a $\mathrm{NaCl}$ solutions of $0.0,1.0,2.0,3.0$ and $4.0 \mathrm{dS}$ $\mathrm{m}^{-1}$ to observe the swelling equilibrium at room temperature. The recovered SAPs ( $1.0 \mathrm{~g})$ was immersed in one of the five concentrations using tea bag method according to Buchholz (1998). The bags were taken out from the solution each 5 minute interval after immersing. The excess of water was wiped superficially with filter paper to remove surface-bound water then weighted. The weight wetted SAPs was recorded till sixty minutes. 
The water absorbency (WAC, g water $\mathrm{g}^{-1}$ SAPs) was calculated using the following equation:

$W A C=\frac{W 2-W 1}{W 1}$

where $\mathrm{W}_{1}$ is the weight of dry SAPs and $\mathrm{W}_{2}$ is the weight of equilibrated swollen SAPs. WAC was calculated as grams of water per gram of dry SAPs.

\section{Short equilibrium experiment (6 minutes)}

Interestingly, the water absorption by recovered SAPs was found to be rapid and high in water or solution initially. So, we conducted an experiment to study the water sorption behavior of SAPs in a short time at shorter intervals. Similar experiments were conducted for 6 minutes immersing time. One gram of dry SAPs was immersed in $\mathrm{NaCl}$ solutions with $0.0,0.5,1.0,2.0$, and $3.0 \mathrm{dS} \mathrm{m}^{-1}$ to observe the swelling equilibrium at room temperature. The tea bags were taken out from the solution each minute and the mass of wetted SAPs was recorded up to six minutes. The determination of water absorbency (WAC) in different saline solutions was as that in the above-mentioned experiments.

\section{Analysis of water absorbency measurements}

Data were analyzed with nonlinear regression models. For describing the relationship between water absorbance parameters and absorbing time, salinity levels or SAPs levels. Polynomials of different orders were used:

First-order polynomial

$$
P(x)=a+b x
$$

Or the second-order polynomial

$$
P(x)=a+b x+c x^{2}
$$

Or the third-order polynomial

$$
P(x)=a+b x+c x^{2}+d x^{3}
$$

where $\mathrm{P}(\mathrm{x})$ is the polynomial value at $\mathrm{x}$ (i.e., SAPs level, salinity level or absorbing time) and $a, b, c$, and $d$ are polynomial coefficients. Equations (2) were fitted to the average values of any absorbance measurements to determine the polynomial coefficients. Differentiating Equations (2) with respect to $\mathrm{x}$ returns the response of such an absorbance parameter to the change of $x$. The minimum equilibrium time for water absorbance by SAPs and the salinity threshold for water absorbance were determined by differentiating any of the concomitant Equations (2).

\section{Water retention capacity of soil amended with saps}

The goal of this test was to assess the effect of the SAPs amendment on the soil moisture storage over five wetting/drying cycles. In this test, swollen SAPs were used. The soil used in this study was collected from newly reclaimed lands in EL-Bostan region, EL-Beheira province, Egypt. El-Bostan region is located at $30.2^{\circ} \mathrm{N} \& 30.5^{\circ} \mathrm{E}$ at an altitude $7.4 \mathrm{~m}$. The soil samples were air dried, sieved through a $2 \mathrm{~mm}$ sieve and oven dried at $105.0^{\circ} \mathrm{C}$ for $24 \mathrm{~h}$. The soil texture is sandy clay loam, with a sand, silt and clay content of $70.0,5.0$ and $25.0 \%$, respectively. The soil $\mathrm{pH}$ is 8.16 and its salinity of $1.5 \mathrm{dS} \mathrm{m}^{-1}$. Moistures stored by $1.0 \mathrm{~kg}$ of the sandy soil amended with different levels of swollen SAPs $(0.0,0.4,0.67,0.8$, and $1.6 \%$ based upon the dry weight of SAPs) were assessed. PVC columns $(8.0 \mathrm{~cm}$ diameter, sealed from the bottom and provided with a fine metal mesh) were used with a rubber tube inserted in the bottom of the column to drain excess water. The swollen SAPs were uniformly mixed with the soil. The SAPs-treated soils were added into the columns and the mixture was compacted to an approximate bulk density of $1.5 \mathrm{Mg} \mathrm{m}^{-3}$ using appropriate blows of a hammer. The soil columns were saturated from the bottom using tap water $\left(0.5 \mathrm{dS} \mathrm{m}^{-1}\right)$, at room temperature $\left(20 \pm 2{ }^{\circ} \mathrm{C}\right)$, once saturated, the columns were allowed to drain the excess water overnight. Soil columns were weighted and the WHC of the soil was determined (Agaba et al., 2010). Soil columns were allowed to dry, at room temperature, until no significant changes in the weight was observed. The method was repeated for the 2nd, 3rd, and 4th wetting/drying cycle. After 6 months from the $1^{\text {st }}$ wetting, the columns were subjected to the $5^{\text {th }}$ rewetting cycle.

To evaluate the ability of the soil-SAPs mixtures to absorb and retain water, three criteria were used.

1. The Water holding capacity of the soil-SAPs mixture (expressed in terms of mass) was calculated as follows (Yu et al., 2017):

$W H C=\frac{W w-W d}{W d}$

where $\mathrm{W}_{\mathrm{w}}$ and $\mathrm{W}_{\mathrm{d}}$ are the final wetted and dry weight of the mixture, respectively.

2. The normalized fraction of water retained (NFWR), which was calculated as follows:

$N F W R=\frac{W A m-W d}{W A s}$

where $\mathrm{WA}_{\mathrm{m}}$ is the average water absorbed by the soil-SAPs mixture; and $\mathrm{WA}_{\mathrm{s}}$ is the average water absorbed by the soil alone (control soil).

3. Specific amount of water retained (SWR)

It is also of interest to evaluate the specific amount of water retained (SWR, $\mathrm{g} \mathrm{g}^{-1}$ ) by a unit weight of SAP in the 
soil-SAP mixture at a given level of SAP which was calculated as follows (Yu et al., 2017):

$S W R=\frac{(D-b)}{C}$

where $D$ is the wet weight of the soil-SAPs mixture $(\mathrm{g}), b$ is the wet weight of soil only $(\mathrm{g})$ and $C$ is the dry weight of SAPs in the soil-SAPs mixture (g).

\section{Results and Discussion}

Two types of experiments were conducted. The objective of the first experiment was to evaluate and describe the effects of four different water salinity levels and absorption time on the water absorbency of recovered SAPs from disposable diapers. The measured water absorbency parameters (WAC and WAR) were also described using polynomial functions to estimate the

Table 1: Polynomial equations of water absorption capacity (WAC), $R^{2}$, absorption rate (dQ/dt) and equilibrium time (Eq. time) for water absorbency under different water salinity for a short absorbing time

\begin{tabular}{|c|c|c|c|c|}
\hline $\begin{array}{l}\text { Salinity } \\
\text { dS } \text { m }^{-1}\end{array}$ & WAC $=a x^{3}+b x^{2}+c x+d$ & $\mathbf{R}^{2}$ & dQ/dt (1/minute) & Eq. time (minute) \\
\hline 0 & WAC $=0.7407 x^{3}-11.876 x^{2}+70.735 x-0.759$ & 0.99 & $=2.2221 \mathrm{x}^{2}-23.752 \mathrm{x}+70.735$ & 5.34 \\
\hline 0.5 & WAC $=0.9691 x^{3}-13.589 x^{2}+68.664 x-0.318$ & 0.99 & $=2.9073 x^{2}-27.178 x+68.664$ & 4.67 \\
\hline 1 & $W A C=0.8148 x^{3}-11.136 x^{2}+55.435 x+0.7672$ & 0.99 & $=2.4444 \mathrm{x}^{2}-22.272 \mathrm{x}+55.435$ & 4.56 \\
\hline 2 & $\mathrm{WAC}=0.9599 \mathrm{x}^{3}-11.903 \mathrm{x}^{2}+52.221 \mathrm{x}+0.6402$ & 0.99 & $=2.8797 \mathrm{x}^{2}-23.806 \mathrm{x}+52.221$ & 4.13 \\
\hline 3 & $\mathrm{WAC}=0.7438 \mathrm{x}^{3}-9.5304 \mathrm{x}^{2}+45.369 \mathrm{x}+1.3254$ & 0.99 & $=2.2314 x^{2}-19.0608 x+46.369$ & 4.27 \\
\hline 4 & $W A C=0.5648 x^{3}-7.8876 x^{2}+38.28 x+1.4312$ & 0.98 & $=1.6944 \mathrm{x}^{2}-15.7752 \mathrm{x}+38.28$ & 4.66 \\
\hline
\end{tabular}

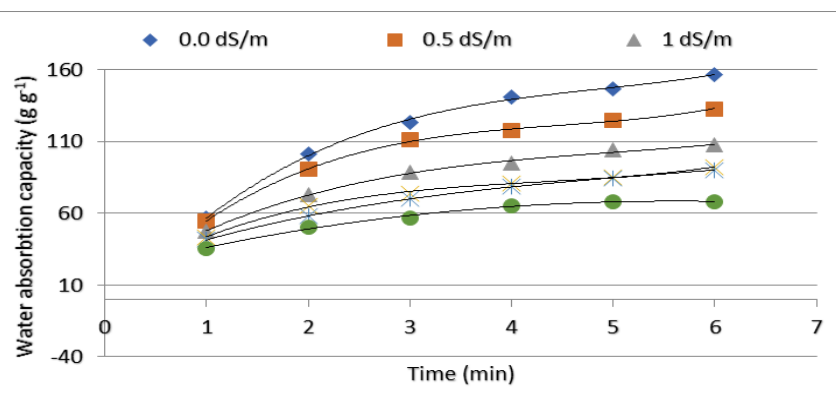

Figure 1: Water absorption capacity (WAC, $\mathrm{g}$ water $\mathbf{g}^{-}$ ${ }^{1}{ }_{\mathrm{SAPs}}$ ) as a function of absorption time (minutes) under different ionic strength $\left(\mathrm{dS} \mathrm{m}^{-1}\right)$. Short absorbing time experiment (6 minutes)

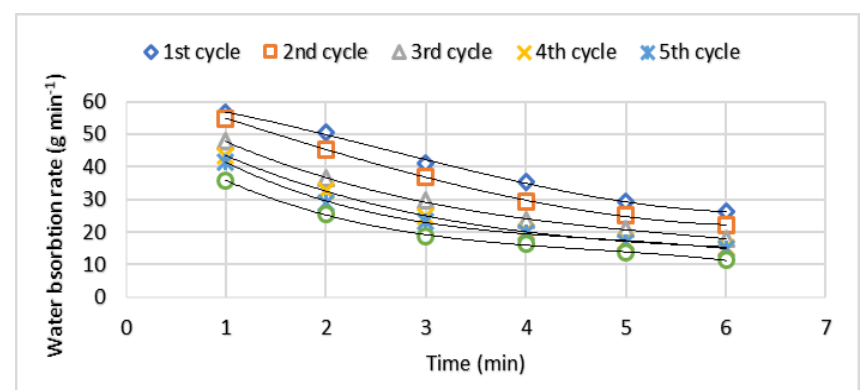

Figure 2: The water absorbency rate $\left(\mathrm{g}_{\text {water }} \mathrm{min}^{-1}\right)$ as a function of absorbing time (minutes) under different ionic strength $\left(\mathrm{dS} \mathrm{m}^{-1}\right)$. Short absorbing time experiment (6 minutes) equilibrium time for water absorbency. The change of WAR with time or water salinity levels, and the threshold salinity for the SAPs were also determined. The objective of the second experiment was to evaluate the effects of recovered SAPs levels on the soil-SAPs water absorbency and water holding capacity of the soil over five rewetting cycles (6 months).

\section{Salt solution absorbency measurements}

\section{Short equilibrium experiment ( 6 minutes)}

The WAC $\left(\mathrm{g} \mathrm{g}^{-1}\right)$ was described using $3^{\text {rd }}$ order polynomial equations as a function of absorbing time under different ionic strength of a solution $\left(\mathrm{dS} \mathrm{m}^{-1}\right)$. The polynomial forms are shown in Table (1) and the observed and calculated WAC values are shown in Figure (1). The polynomial equation described more than $98 \%$ of the variations in WAC under different water salinity. The WAC positively depended on the absorbing time. The distributions of WAC with time behaved in two distinguished stages. In the first stage, the WAC increased fast till 3.0 to 4.0 minutes while it increased gradually during the second stage (5.0 to 6.0 minutes). The water absorbency was high during the first stage because of the high-water potential gradient between the solution media and the SAPs. This gradient decreased over time increases during the second stage which resulted in a gradual increase in WAC. Similar distribution of water absorbency with drying time using different SAPs types (Yu et al., 2017) and different SAPs particle sizes (Abdallah 2019) were observed. Effects of water salinity on 
the water absorbency were negative; the free water $(0.0 \mathrm{dS}$ $\mathrm{m}^{-1}$ ) showed the greatest WAC while the solution with salinity of $4 \mathrm{dS} \mathrm{m}^{-1}$ possessed the lowest WAC during the whole absorbing time. Akhter et al. (2004) found that water absorption by SAPs decreased with an increase in water salinity with maximum absorption in distilled water (505.0 $\left.\mathrm{g} \mathrm{g}^{-1}\right)$ followed by tap water $\left(212.0 \mathrm{~g} \mathrm{~g}^{-1}\right)$ and saline water $\left(140.0 \mathrm{~g} \mathrm{~g}^{-1}\right)$. The $3^{\text {rd }}$ polynomial was also used to calculate the WAR (Table 1 and Figure 2) which is equal to its first derivative $(\mathrm{dy} / \mathrm{dx})$. The WAR decreased greatly with time. Water salinity reduced the WAR as well. The salinity of 0.0 $\mathrm{dS} \mathrm{m}{ }^{-1}$ gave high water absorbing rate in comparison with others salinity levels. application rate or emitter discharge. Yu et al. (2011) reported an equilibrium time of 10.0 minutes for different types of SAPs. They found that the amount of water absorbed by SAPs was not significantly different among four soil textures after 10.0 minutes of wetting. This observation suggested that confinement by the solid matrix was the main mechanism controlling water absorption by the soil-SAPs mixtures rather than soil properties.

\section{Long equilibrium experiment (60 minutes)}

Similar to the short time experiment, the WAC was determined as a function of time and salinity. The WAC was recorded every 5.0 minutes for 60.0 minutes. The WAC

Table 2: Polynomial equations for water absorption capacity (WAC), $\mathbf{R}^{2}$, and absorption rate (dy/dx) under different water salinity for a long absorbing time

\begin{tabular}{llll}
\hline Salinity $(\mathbf{d S} / \mathbf{m})$ & WAC $=\mathbf{a x}+\mathbf{b} \mathbf{x}^{2}+\mathbf{c x}+\mathbf{d}$ & $\mathbf{R}^{\mathbf{2}}$ & $\mathbf{d Q} / \mathbf{d t}(\mathbf{1} / \mathbf{m i n u t e})$ \\
\hline 0 & WAC $=0.0033 \mathrm{x}^{3}-0.3804 \mathrm{x}^{2}+14.608 \mathrm{x}+96.388$ & 0.96 & $=0.0099 \mathrm{x}^{2}-0.7608 \mathrm{x}+14.608$ \\
0.5 & WAC $=0.0007 \mathrm{x}^{3}-0.0943 \mathrm{x}^{2}+4.7388 \mathrm{x}+106.02$ & 0.98 & $=0.0021 \mathrm{x}^{2}-0.1886 \mathrm{x}+4.7388$ \\
1 & WAC $=0.0013 \mathrm{x}^{3}-0.1636 \mathrm{x}^{2}+6.8955 \mathrm{x}+78.532$ & 0.97 & $=0.0039 \mathrm{x}^{2}-0.3272 \mathrm{x}+6.8955$ \\
2 & WAC $=0.0004 \mathrm{x}^{3}-0.0593 \mathrm{x}^{2}+3.253 \mathrm{x}+71.838$ & 0.98 & $=0.0012 \mathrm{x}^{2}-0.1186 \mathrm{x}+3.253$ \\
3 & WAC $=-0.0009 \mathrm{x}^{3}+0.0874 \mathrm{x}^{2}-1.5161 \mathrm{x}+85.281$ & 0.95 & $=-.0027 \mathrm{x}^{2}-0.1748 \mathrm{x}+1.5161$ \\
\hline
\end{tabular}

$\mathrm{X}=$ time (minute)

$\mathrm{R}^{2}=$ the coefficient of determination

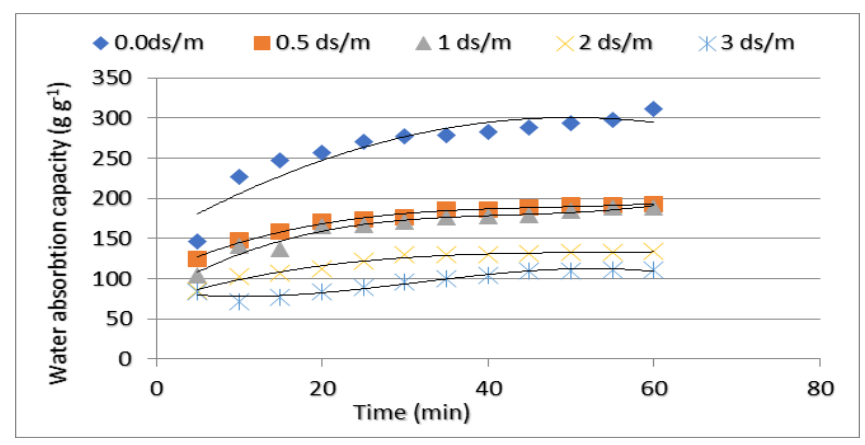

Figure 3: The water absorption capacity (WAC, $g_{\text {water }} \mathbf{g}^{-}$ ${ }^{1}{ }_{\text {SAPs) }}$ as a function of absorbing time (minutes) under different ionic strength $\left(\mathrm{dS} \mathrm{m}^{-1}\right)$. Long absorbing time experiment (60 minutes)

The equilibrium time of SAPs is a vital factor in irrigation water management especially in light-textured soils. This time is an indicator for the maximums water absorbency by SAPs. The second derivative of the $3^{\text {rd }}$ polynomial is useful for the calculation of the equilibrium time. Table (1) showed the equilibrium time of SAPs at each level of water salinity. The equilibrium times were 5.34, $4.67,4.55,4.13,4.20$ and 4.60 minutes for $0.0,1.0,2.0,3.0$ and $4.0 \mathrm{dS} \mathrm{m}^{-1}$, respectively. The average equilibrium time for the six salinity levels was 4.6 minutes. Additionally, the equilibrium time might be useful in designing and operating such an irrigation system, particularly in setting water similarly behaved to the previous short equilibrium experiment with a lower WAR for any given salinity levels. Therefore, the distributions of WAC over time is described well with polynomial equations with high $\mathrm{R}^{2}$. The fitted equation parameters, $\mathrm{R}^{2}$, and its first derivative are presented in Table (2). The measured and estimated WAC as a function of time under different water salinity are shown in Figure (3). Both observed and estimated values of WAC were highly correlated. The $\mathrm{R}^{2}$ were $0.96,0.99,0.97$, 0.98 and 0.95 for salinity values of $0.0,0.5,1.0,2.0$ and 3.0 $\mathrm{dS} \mathrm{m}{ }^{-1}$, respectively. The WAC values increased with time and decreased with increasing water salinity. The recovered SAPs had a higher WAC when applying distilled water, with a maximum WAC of $311.0 \mathrm{~g} \mathrm{~g}^{-1}$. The ability of the SAPs to absorb a significant amount of water was well established in many studies (Orokiriza et al., 2013; Banedjschafie and Durner 2015). The WAC of SAPs might be due to their high negative charge, molecular weight, and cross-linking density (Spagnol et al., 2012a). The negative effect of salinity on the WAC of SAPs has been reported in several studies (Bai et al., 2013; B et al., 2013owman et al., 1990; Wang and Gregg1990) that might be attributed to the formation of salt-polymer complexation (Akhter et al., 2004; Spagnol et al., 2012b). The cations are attached to the carboxylic acid groups and block the active negative sites (Zhou et al., 2012). Even under high levels of water salinity $\left(4.0 \mathrm{dS} \mathrm{m}^{-1}\right)$, the recovered SAPs absorbed a significant 
amount of water $\left(111.0 \mathrm{~g} \mathrm{~g}^{-1}\right)$. The results of WAC for the long equilibrium time is in consistency with the results of short equilibrium time previously parented. Similar results
$1.02 \mathrm{~g} \mathrm{~min}^{-1}$ at $3.0 \mathrm{dS} \mathrm{m}^{-1}$ for an absorption time of 5 minutes. At the absorption time of 60.0 minutes, the corresponding $\mathrm{dQ} / \mathrm{dt}$ values were 0.21 and $0.08 \mathrm{~g} \mathrm{~min}^{-1}$,

Table 3: Effect of water salinity on water absorption capacity (WAC) at different time during a long absorbing time

\begin{tabular}{cllr}
\hline Absorbing time (minute) & $\mathbf{Q}=\mathbf{a x} \mathbf{2}^{\mathbf{2}} \mathbf{b x}+\mathbf{c}$ & $\mathbf{R}^{\mathbf{2}}$ & ${\text { Maximum salinity }\left(\mathbf{d S} \mathbf{~ m}^{\mathbf{- 1}}\right)}$ \\
\hline 15 & $\mathrm{WAC}=19.392 \mathrm{x}^{2}-108.3 \mathrm{x}+233.12$ & 0.93 & 2.79 \\
20 & $\mathrm{WAC}=17.063 \mathrm{x}^{2}-103.21 \mathrm{x}+243.57$ & 0.94 & 2.02 \\
30 & $\mathrm{WAC}=19.571 \mathrm{x}^{2}-111.8 \mathrm{x}+253.8$ & 0.92 & 2.85 \\
35 & $\mathrm{WAC}=19.885 \mathrm{x}^{2}-112.63 \mathrm{x}+263.84$ & 0.94 & 2.83 \\
45 & $\mathrm{WAC}=23.821 \mathrm{x}^{2}-124.47 \mathrm{x}+273.52$ & 0.93 & 2.61 \\
\hline
\end{tabular}

$\mathrm{x}=$ salinity level $\left(\mathrm{dS} \mathrm{m}^{-1}\right)$

$\mathrm{R}^{2}=$ the coefficient of determination

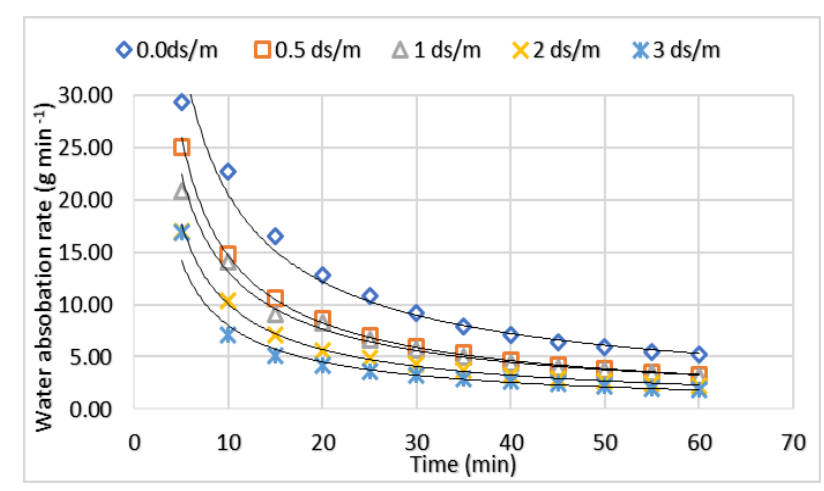

Figure 4: The water absorbency rate $\left(\mathrm{g} \mathrm{min}^{-1}\right)$ as a function of absorbing time (minutes) under different ionic strength $\left(\mathrm{dS} \mathrm{m}^{-1}\right)$. Long absorbing time experiment (60 minutes)

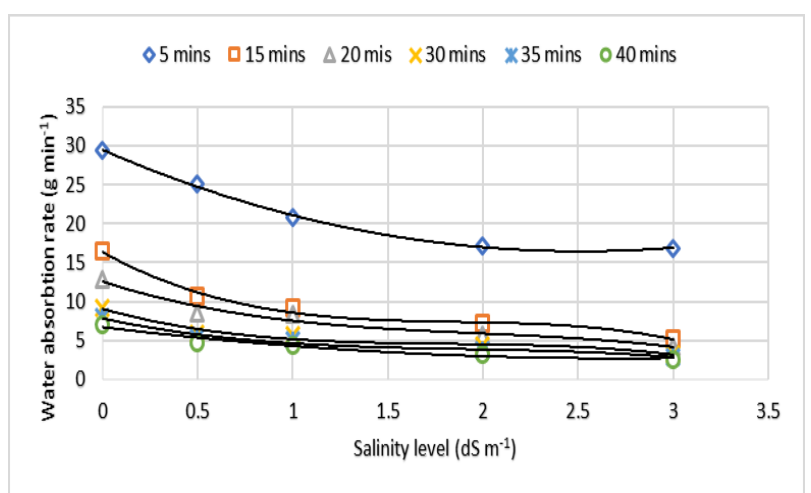

Figure 5: Effect of water salinity on water absorption rate $\left(\mathrm{g} \mathrm{min}^{-1}\right)$ at different time. Long absorbing time experiment (60 minutes)

of WAC were reported by Akhter et al. (2004) and Abdallah (2019). The WAR, observed in the present study $(\mathrm{dQ} / \mathrm{dt})$, decreased as the water salinity increased (Figure 4). For example, the $\mathrm{dQ} / \mathrm{dt}$ was $2.79 \mathrm{~g} \mathrm{~min}^{-1}$ at $0.0 \mathrm{dS} \mathrm{min} \mathrm{m}^{-1}$ and respectively. Therefore, using water of low quality will reduce the usefulness of SAPs in soil water management. These low-quality waters will reduce the enhancement of SAPs for the plant available water.

The effect of water salinity on SAPs water absorbency (WAC) was described using $3^{\text {rd }}$ order polynomials at different times for the long absorbing time experiment. The polynomial described well the variations of $\mathrm{Q}$ at absorbing time of $15.0,20.0,30.0,35.0$ and 45.0 minutes. The corresponding $\mathrm{R}^{2}$ were $0.94,0.95,0.93,0.94$ and 0.94 . The polynomial and $\mathrm{R}^{2}$ are shown in Table (3). The observed and estimated WAC values are shown in Figure (5). There was good agreement between the observed and estimated values. The first derivative of the $3^{\text {rd }}$ order polynomial was set to zero. The resulting equation for $1^{\text {st }}$ derivative was solved in order to define the salinity level that represents salinity threshold. The $1^{\text {st }}$ derivative for the five selected absorbing time is shown in Table (4). The threshold salinity $\left(\mathrm{dS} \mathrm{m} \mathrm{m}^{-1}\right)$ for the absorbing times was $2.79,3.02,2.85,2.83$ and 2.61 for absorbing times of 15.0, 20.0, 30.0, 35.0 and 45.0 minutes, respectively. The average value of the salinity threshold was $2.78 \mathrm{dS} \mathrm{m}^{-1}$. It is inferred that water absorption by SAPs might be negligible at $2.78 \mathrm{dS} \mathrm{m}^{-1}$. Accordingly, it is concluded that irrigation water salinity above $2.78 \mathrm{dS} \mathrm{m}^{-1}$ might reduce the usefulness of the uses of SAPs in water management strategy.

\section{Water retention capacity of saps-amended soil under rewetting cycles}

Figure (6) presents the effect of SAPs levels and rewetting cycle on the measured and estimated WHC. The obtained results indicated that the WHC of SAPs-treated soil is a function of SAPs concentration and rewetting cycle. The observed values were fitted to a $1^{\text {st }}$ order polynomial (Eq. 2a). The polynomial described more than 94.0 to $99.0 \%$ of the variations of WHC that ensure the 
goodness of the linear equation used (Table 4) under the five rewetting cycles.

Table 4: Effect of rewetting cycle on the water holding capacity (WHC) of the soil under different levels of super absorbent polymers (SAPs) using a linear equation

\begin{tabular}{lll}
\hline Rewetting cycle No. & WHC $=\mathbf{a x}+\mathbf{b}$ & $\mathbf{R}^{\mathbf{2}}$ \\
\hline $1^{\text {st }}$ & $=0.1949 \mathrm{x}+0.1964$ & 0.99 \\
$2^{\text {nd }}$ & $=0.1867 \mathrm{x}+0.1868$ & 0.99 \\
$3^{\text {rd }}$ & $=0.1924 \mathrm{x}+0.1689$ & 0.99 \\
$4^{\text {th }}$ & $=0.18 \mathrm{x}+0.1614$ & 0.97 \\
$5^{\text {th }}$ & $=0.1918 \mathrm{x}+0.1532$ & 0.94 \\
\hline
\end{tabular}

$\mathrm{x}=$ amount of SAPs $(\%)$

$\mathrm{R}^{2}=$ the coefficient of determination

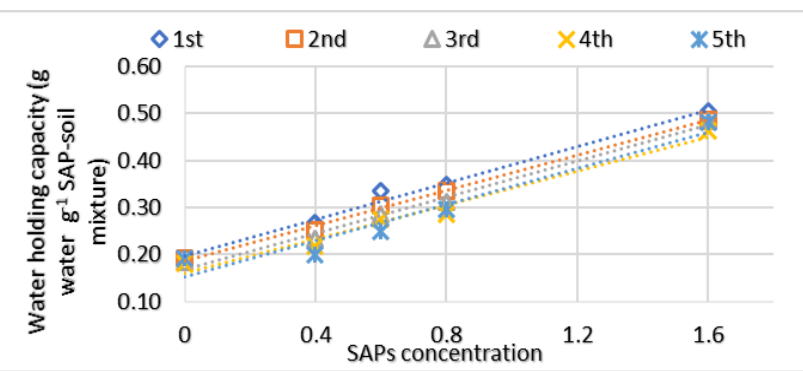

Figure 6: Effect of super absorbent polymers (SAPs) level and rewetting cycle on the water holding capacity of the soil (WHC, $g$ water $\mathrm{g}^{-1}$ SAPs-soil mixture) of the SAPs-soil mixture
The WHC values increase as the levels of SAPs increase linearly. The WHC ranged from 0.19 to $0.50 \mathrm{~g} \mathrm{H}_{2} \mathrm{O}$ $\mathrm{g}^{-1}$ SAPs-soil mixture for 0.0 to $1.6 \%$ SAPs level, respectively, for the first wetting cycle. So, when this SAPs is mixed with the sandy soil, the mixture might able to lose water slowly (Abdallah 2019). The positive effect of SAPs from disposable diapers, on soil WHC has been previously observed by (Qu and de Varennes, 2010; Sánchez-Orozco et al., 2017; Al-Jabari et al., 2019;). Yu et al. (2017) for different soil textures and different kinds of SAPs in which they found that water absorption increased with an increase in SAPs concentration and soil clay content. Rewetting negatively affected the WHC because the slope of linear function decreases as the repeated wetting increase (Figure 7a). The observed soil WHC as a function of rewetting cycles was described using linear equations with $\mathrm{R}^{2}$ ranged from 0.93 to 0.99 for the $0.4,0.6$ and 0.8 concentrations (Table 5). However, the linear equation did not describe well the WHC at the high level of SAPs because the $\mathrm{R}^{2}$ value was 0.57 . Interestingly, the WHC decreased slightly as the SAPs level increased. For example, after five rewetting cycles, the WHC was reduced by $25.0 \%$ and $5.0 \%$ for SAPs concentration of $0.4 \%$ and $1.6 \%$, respectively. The average soil WHC dropped from 0.33 to be 0.28 for the $1^{\text {st }}$ and $5^{\text {th }}$ cycle, respectively; amounting to a reduction of $14 \%$ (Figure $7 \mathrm{~b}$ ). Repeated wetting/drying reduced the positive effect of SAPs application, noticing that the greatest reduction was in the first 4 watering cycles. Our

Table 5: linear equation for describing the effect of super absorbent polymers (SAPs) level and rewetting cycle on the water holding capacity (WHC) of the soil and its rate (d(WHC)/dx)

\begin{tabular}{llll}
\hline SAPs Concentration. & $\mathrm{WHC}=\mathrm{a}(\mathrm{x})+\mathrm{b}$ & $\mathrm{R}^{2}$ & $\mathrm{~d}(\mathrm{WHC}) / \mathrm{dx}(\%$ of SAPs $)$ \\
\hline 0.4 & $\mathrm{WHC}=-0.0168 \mathrm{x}+0.2846$ & 0.99 & -0.016 \\
0.6 & $\mathrm{WHC}=-0.0198 \mathrm{x}+0.3491$ & 0.97 & -0.019 \\
0.8 & $\mathrm{WHC}=-0.0158 \mathrm{x}+0.3627$ & 0.86 & -0.015 \\
1.6 & $\mathrm{WHC}=-0.0072 \mathrm{x}+0.5051$ & 0.57 & -0.007 \\
Average WHC & $\mathrm{WHC}=-0.0121 \mathrm{x}+0.3382$ & 0.95 & -0.012 \\
\hline
\end{tabular}

$\mathrm{x}=$ amount of SAPs (\%)

$\mathrm{R}^{2}=$ the coefficient of determination

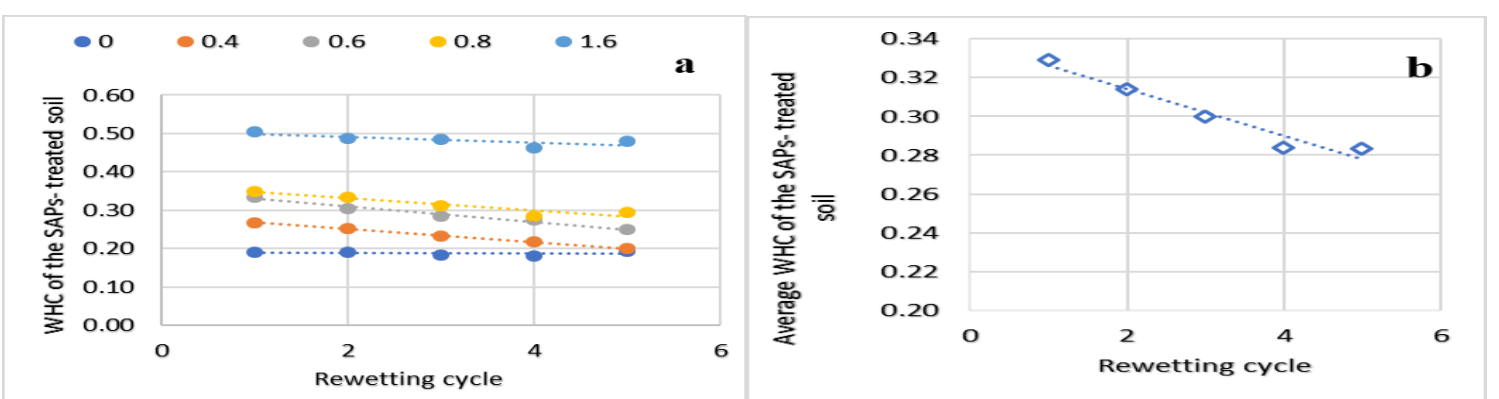

Figure 7: (a) Effect of rewetting cycle and super absorpent polymers (SAPs) level on the water holding capacity of the SAPs-soil mixture (WHC, g water $\mathrm{g}^{-1}$ SAPs-soil mixture). (b) Average water holding capacity of the SAPs-soil mixture (WHC, $\mathrm{g}$ water $\mathrm{g}^{-1}$ SAPs-soil mixture) as affected by rewetting cycle 
results are confirmed in several studies which report that repeated wetting reduced SAPs' efficiency by $50 \%$ after three months (Banedjschafieand Durner, 2015) and by $30.0 \%$ after 77 days (Geesing and Schmidhalter, 2004). The aging effect might be attributed to the decomposition of SAPs (Smagin et al., 2014). However, the pattern of the WHC with time (Figure $7 b$ ) opposes the decomposition theory, where a significant reduction in WHC was observed

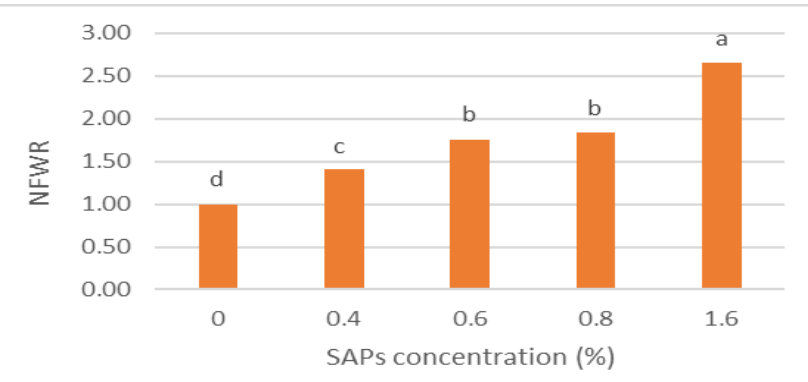

Figure 8: Effect of super absorbent polymers (SAPs) level on the normalized fraction of water retained NFWR ( $1^{\text {st }}$ wetting cycle). Values are the mean \pm SD $(n=3)$. Significant differences between treatments at $p$-value $\leq 0.05$ (Tukey's test) indicated by different letters from the $1^{\text {st }}$ to $4^{\text {th }}$ rewetting cycles, but then it was stable in the $4^{\text {th }}$ and $5^{\text {th }}$ cycles. The aging effect might be due to salinity (from soil and irrigation water) which affects the WAC of the tested SAPs. With the declining WAC, the capacity of SAPs to hold the water was weakened. Yu et al. (2011) attributed the aging effect to the release of $\mathrm{Ca}^{2+}$ and $\mathrm{Mg}^{2+}$ from soil and irrigation water. It is concluded that the efficiency of water storage for this kind of SAPs decreases as rewetted and its ability to water absorption is reduced inconsiderably by rewetting. This is a promising result as it could be informing the management of irrigation strategy under field condition using SAPs. Even though a significant reduction was observed, recovered SAPs were still functional and able to conserve a significant amount of water as compared to the control soil.

The normalized fraction of water retained (NFWR) as a function of SAPs levels and rewetting cycle is another index to explain the SAPs levels and rewetting cycle effects on the ability of soil-SAPs mixture to store water. Figure (8) shows the NFWR as a function of SAPs levels for the first wetting cycle. The NFWRs were 1.0, 1.41, 1.76, 1.84 and 2.65 for the SAPs levels of 0.0, 0.4, 0.6, 0.8 and $1.6 \%$, respectively, for the first wetting cycle. The NFWR for the high-level SAPs was 2.65 folds as the un-amended soil by SAPs. These results of NFWR confirm the aforementioned results

Table 6: linear equation and $R^{2}$ for describing the effect of super absorbent polymers (SAPs) level and rewetting cycle on the specific amount of water retained (SWR) and its rate (d(SWR)/dx)

\begin{tabular}{llll}
\hline SAPs Concentration. & $\mathbf{S W R}=\mathbf{a}(\mathbf{x})+\mathbf{b}$ & $\mathbf{R}^{\mathbf{2}}$ & $\mathbf{d}(\mathbf{S W R}) / \mathbf{d x}(\mathbf{k g} / \mathbf{g})$ \\
\hline 0.4 & $=-4.0501 \mathbf{x}+23.783$ & 0.95 & $=-4.050$ \\
0.6 & $=-3.1999 \mathrm{x}+26.611$ & 0.94 & $=-3.199$ \\
0.8 & $=-1.8957 \mathrm{x}+21.654$ & 0.96 & $=-1.895$ \\
1.6 & $=-0.4125 \mathrm{x}+19.729$ & 0.70 & $=0.412$ \\
Average & $=-2.3896 \mathrm{x}+22.944$ & 0.98 & $=-2.389$ \\
\hline
\end{tabular}

$\mathrm{x}=$ amount of SAPs $(\%)$

$\mathrm{R}^{2}=$ the coefficient of determination
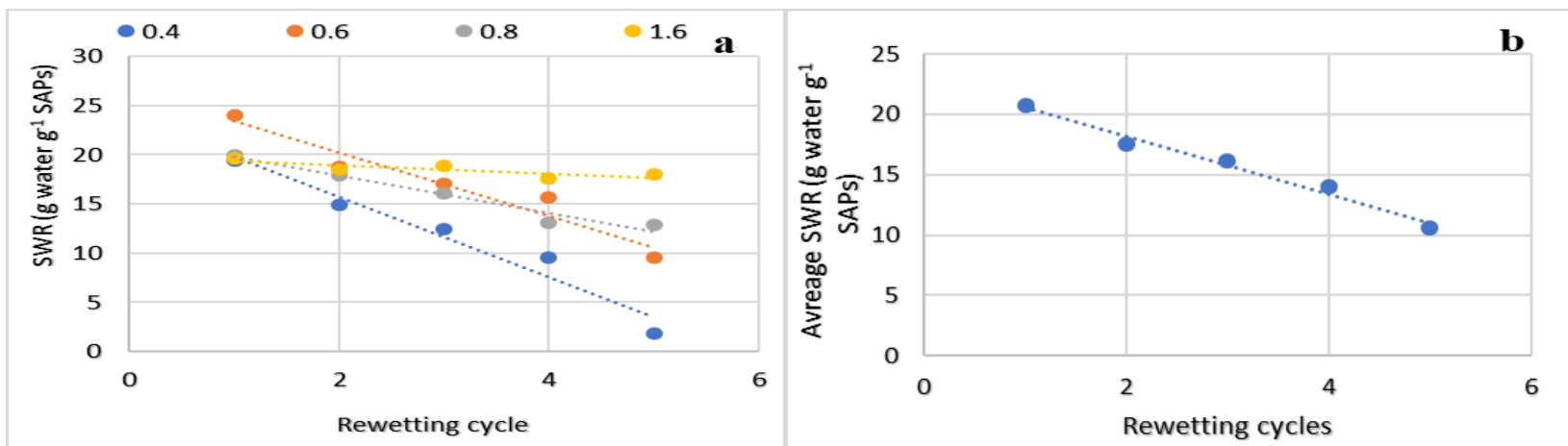

Figure 9: (a) Effect of super absorpent polymers (SAPs) level and rewetting cycle on the specific amount of water retained SWR (g water $\mathrm{g}^{-1}$ SAPs) by SAPs in of the SAPs-soil mixture. (b) Average specific amount of water retained SWR (g water $\mathrm{g}^{-1}$ SAPs) by SAPs in of the SAPs-soil mixture as affacted by rewetting cycle 
for the SAPs positive effects on the WHC of the soil. Effects of rewetting cycle on the NFWR were negative with repeated wetting (data are not shown). This reduction in the water absorbed by rewetting cycle might due to salinity of soil and irrigation water. Similarly, Akhter et al. (2004) found that the gel had high water absorption during the first wetting, and it decreased during subsequent wetting cycles, and increasing salt content in the water applied.

The results presented in figure (9) illustrate effects of SAPs level and rewetting cycles on the specific amounts of water retained (SWR) by the soil-SAPs mixtures. It is interesting to note that the SWR decreased nonlinearly as the SAPs level increased. A linear equation described the measured SWR well with $\mathrm{R}^{2}$ ranging from 0.93 to 0.99 for the $0.4,0.6$ and 0.8 concentrations, respectively, but the $\mathrm{R}^{2}$ value for the highest concentration was equal to 0.70 . The rewetting cycle affected the SWR negatively with increasing the rewetting cycles. The change rate of SWR can be obtained by differentiating the liner equation shown in Table (6) for each rewetting cycle. These rates represent the amount of water retained by unit mass of soil for each SAPs level. The rewetting cycle effects were more pronounced at low level of SAPs than at high level of SAPs (Figure 9a). Consequently, the lower concentration showed a significant downward trend compared to the high concentration (1.6\%). The average SWR (Figure 9b) dropped from $20.73 \mathrm{~g}$ water $\mathrm{g}^{-1}$ SAPs in the $1^{\text {st }}$ cycle to 10.73 in the $5^{\text {th }}$ cycle (after 6 months). The observed downward trend in SWR with repeated wetting was also found by different authors ( Han et al., 2013; Banedjschafie and Durner 2015). These results show that the ability of the SAPs to absorb water in the soil was reduced in comparison to the absorption from free water or poor-quality water. The maximum WAC of the SAPs in the water was $311.0 \mathrm{~g} \mathrm{~g}^{-1}$, however, the maximum WAC in the SAPs-soil mixture was $20.73 \mathrm{~g} \mathrm{~g}^{-1}$. These results are in agreement with results of (Buchholz, 1998; Bhardwaj et al., 2007 and Yu et al., 2011). The presence of a soil matrix limited SAPs swelling, as subjected to a pressure from all directions by soil particles and thus restricting water absorption by the SAPs in the mixtures $(\mathrm{Yu}$ et al., 2017). Another reason might be that the salt released from the soil reduced the WAC of the tested SAPs. After all, since the polymers in diapers are $\mathrm{Na}^{+}$based, therefore, the biggest limitation for diapers application is the expected soil degradation due to $\mathrm{Na}^{+}$. The negative effect of $\mathrm{Na}^{+}$might be mitigated by Gypsum application. Further research is needed to investigate the combined effect of gypsum and polymers from diapers to enhance the WHC of the soil, while reducing the possible hazard due to $\mathrm{Na}^{+}$. This paper is a part of a big study that aimed to investigate the potential of diapers recycling for afforestation project in Egypt, using sewage water. Therefore, this type of SAPs might be recommended under afforestation projects when sewage water is used.

\section{Conclusion}

Two experiments were conducted in the present work to investigate the potential of diapers recycling in agriculture. The objective of the first experiment was to evaluate effects of four different water salinity levels and time on the SAPs water absorbency. The water absorbency measurements were modeled using different order polynomials functions to estimate the equilibrium time for water absorbency, the change of absorbency rates with time or water salinity levels, and the threshold salinity for the SAPs. The objective of the second experiment was to evaluate the effect of SAPs levels from used diaper on the soil-SAPs water absorbency with five rewetting cycles. The recovered SAPs showed high affinity to water since the WAC was $311.0 \mathrm{~g} \mathrm{~g}^{-1}$. The WAC increased as time of immersing increased and showed a nonlinear response to different salinity levels. Increasing the salinity of swelling media reduced the water absorbency of SAPs nonlinearly. The polynomials were used to define two important parameters for management application of SAPs in the agriculture fields. The parameters are the equilibrium time and salinity threshold of SAPs, which were 4.5 minutes and $2.78 \mathrm{dS} \mathrm{m}^{-1}$, respectively. The WHC of SAPs-soil mixture increased linearly by further increase of the SAPs levels. Increasing the number of rewetting cycles reduced the beneficial effect of the recovered SAPs since the SWR, NFWR and WHC were reduced after 6 months. These reductions might be due to soil and water salinity in addition to the effect of soil particles on the swelling of SAPs. Therefore, the used diaper SAPs is highly recommended for different agricultural applications concomitant with the use of good quality water.

\section{References}

Abdallah, A.M. 2019. International soil and water conservation research the effect of hydrogel particle size on water retention properties and availability under water stress. International Soil and Water Conservation Research 7(3): 275-285.

Agaba, H., L.J.B. Orikiriza, J.F.O. Esegu, J. Obua, J.D. Kabasa, and A. Hüttermann. 2010. Effects of hydrogel amendment to different soils on plant available water and survival of trees under drought conditions. Clean Soil, Air, Water 38(4): 328-335.

Akhter, J., K. Mahmood, K.A. Malik, A. Mardan, M. Ahmad, and M.M. Iqbal. 2004. Effects of hydrogel amendment on water storage of sandy loam and loam 
soils and seedling growth of barley, wheat and chickpea. Plant, Soil and Environment 50(10): 463-469.

Al-Jabari, M., R.A. Ghyadah and R. Alokely. 2019. Recovery of hydrogel from baby diaper wastes and its application for enhancing soil irrigation management. Journal of Environmental Management 1(239): 255261.

Bai, W., J. Song and H. Zhang. 2013. Repeated water absorbency of superabsorbent polymers in agricultural field applications: A simulation study. Acta Agriculturae Scandinavica, Section B - Soil \& Plant Science 63(5): 433-441.

Banedjschafie, S. and W. Durner. 2015. Water retention properties of a sandy soil with superabsorbent polymers as affected by aging and water quality. Journal of Plant Nutrition and Soil Science 178(2002): 798-806.

Bhardwaj, A.K., I. Shainberg, D. Goldstein, D.N. Warrington and G.J. Levy. 2007. Water retention and hydraulic conductivity of cross-linked polyacrylamides in sandy soils. Soil Science Society of America Journal 71(2): 406.

Bowman, D.C., R.Y. Evans and J.L. Paul. 1990. Fertilizer salts reduce hydration of polyacrylamide gels and affect physical properties of gel-amended container media. Horticultural Science 115(3): 382-386.

Buchholz, F.L. 1998. The structure and properties of super absorbents polyacrylates. p.167-221. In: Modern Superabsorbent Polymer Technology. Buchholz and Graham (eds.), John Wiley Sons Inc. Wiley-VCH.

Colón, J., L. Ruggieri, A. Sánchez, A. González and I. Puig. 2010. Possibilities of composting disposable diapers with municipal solid wastes. Waste Management and Research 29: 249-59.

Colón, J., M. Mestre-Monserrat, I. Puig-Ventosa and A. Sánchez. 2013. Performance of compostable baby used diapers in the composting process with the organic fraction of municipal solid waste. Waste Management 33(5): 1097-103.

EDANA, 2008. Sustainability Report 2007e2008:

Absorbent Hygiene Products. EDANA, Brussels.

Accessed on 31.03.14.

https://www.edana.org/docs/default-

source/sustainability/edana-sustainability-report--2007.pdf?sfvrsn=33a7d9b3_2

Espinosa-Valdemar, R.M., L. Delfín-Alcalá and J.L. Contreras. 2003. Kinetic study of batch biodegradation of diapers. The International Journal of Chemical Reactor Engineering 1: 1-6.

Espinosa-Valdemar, R.M., S. Turpin-Marion, I. DelfínAlcalá and A. Vázquez-Morillas. 2011. Disposable diapers biodegradation by the fungus pleurotus ostreatus. Waste Management 31: 1683-8.
Espinosa-Valdemar, R.M., X. Perla, Sotelo-Navarro, X. Quecholac-Pĩna, A. Mariel. García-Rivera, M. BeltránVillavicencio, S. Ojeda-Benítezb and A.V. Morillas. 2014. Biological recycling of used baby diapers in a small-scale composting system. Resources, Conservation \& Recycling 87: 153-157. https://doi.org/10.1016/j.resconrec.2014.03.015

Forkes, J. 2007. Nitrogen balance for the human food metabolism of Toronto, Canada. Resources, Conservation \& Recycling 52: 74-94.

Gerba, C.P., M.S. Huber, J. Naranjo, J.B. Rose and S. Bradford. 1995. Occurrence of enteric pathogens in composted domestic solid waste containing disposable diapers. Waste Management and Research 13:315-24.

Geesing, D. and U. Schmidhalter. 2004. Influence of sodium polyacrylate on the water-holding capacity of three different soils and effects on growth of wheat. Soil Use and Management 20(2): 207-209.

Hafeez-ur-Rahman, G. Nabi, I. Ali, T. Tahir and M. Ahmed. 2012. Growth and yield of Kinnow (Citrus reticulata Blanco) and soil physical properties as affected by orchard floor management practices in Punjab, Pakistan. Soil \& Environment 31(2): 163-170.

Han, B., S.G. Benner, and A.N. Flores. 2018. Evaluating impacts of climate change on future water scarcity in an intensively managed semi-arid region using a coupled model of biophysical processes and water rights. Hydrology and Earth System Sciences Discussions 153.

Han, Y., X. Yu, P. Yang, B. Li, L. Xu, and C. Wang. 2013. Dynamic study on water diffusivity of soil with superabsorbent polymer application. Environmental Earth Sciences 69(1): 289-296.

Hüttermann, A., L.J.B. Orikiriza, and H. Agaba. 2009. Review application of superabsorbent polymers for improving the ecological chemistry of degraded or polluted lands. Clean Soil, Air, Water 37(7): 517-526.

Khoo, S.C., X.Y. Phang, C.M. Ng, K.L. Lim, S.S. Lam and N. Ma. 2019. Recent technologies for treatment and recycling of used disposable baby diapers. Process Safety and Environmental Protection 123: 116-129.

Moghbel, F., B. Mostafazadeh-Fard, S.A.M. Maibody and E. Landi. 2017. Salinity management for irrigation with saline-sodic wastewater under corn cultivation. Soil \& Environment 36(2): 120-130.

Montesano, F.F., A. Parente, P. Santamaria, A. Sannino, and F. Serio. 2015. Biodegradable superabsorbent hydrogel increases water retention properties of growing media and plant growth. Agriculture and Agricultural Science Procedia 4: 451-458.

Orikiriza, L.J.B., H. Agaba, G. Eilu, J.D. Kabasa, M. Worbes and A. Hüttermann. 2013. Effects of hydrogels 
on tree seedling performance in temperate soils before and after water stress. Journal of Environmental Protection 4(7): 713-721.

Puig, V.I. and P.A. González. 2009. Viabilitat de la recollida I el tractment debolquers d'un sol ús a Catalunya. Ent. Spain: Environment and Management; 2009. p. 108. Accessed on 30.12.2019.

$\mathrm{Qu}, \mathrm{G}$. and A. de Varennes. 2010. Use of hydrophilic polymers from diapers to aid the establishment of Spergularia purpurea in a mine soil. Journal of Hazardous Materials 178(1-3): 956-962.

Sánchez-Orozco, R. Beatriz Timoteo-Cruz, T.T. Blancas and F.U. Núñez. 2017. Valorization of superabsorbent polymers from used disposable diapers as soil moisture retainer. International Journal of Research 5(4): 105117. https://doi.org/10.5281/zenodo.569984.

Satriani, A., M. Catalano and E. Scalcione. 2018. The role of superabsorbent hydrogel in bean crop cultivation under deficit irrigation conditions: A case-study in Southern Italy. Agricultural Water Management 195 (January 2018): 114-119.

Smagin, A.V., N.B. Sadovnikova and M.V. Smagina. 2014. Biodestruction of strongly swelling polymer hydrogels and its effect on the water retention capacity of soils. Eurasian Soil Science 47(6): 591-597.

Spagnol, C., F.H.A. Rodrigues, A.G.V.C. Neto, A.G.B. Pereira, A.R. Fajardo, E. Radovanovic, A.F. Rubira and E.C. Muniz. 2012a. Nanocomposites based on poly(acrylamide-co-acrylate) and cellulose nanowhiskers. European Polymer Journal 48(3): 454463.
Spagnol, C., F.H.A. Rodrigues, A.G.B. Pereira, A.R Fajardo, A.F. Rubira and E.C. Muniz. 2012b. Superabsorbent hydrogel composite made of cellulose nanofibrils and chitosan-graft-poly(acrylic acid). Carbohydrate Polymers 87(3): 2038-2045.

UN. (2019). World Population Prospects: The 2019 Revision. United Nations Population Division. https://population.un.org/wpp/Download/Standard/Popu lation/. Accessed on 30.12.2019.

Wang, Y.T. and L.L. Gregg. 1990. Hydrophilic polymers their response to soil amendments and effect on properties of a soilless potting mix. Journal of American Society for Horticultural Science 115(6): 943-948.

Yu, J., I. Shainberg, Y.L. Yan, J.G. Shi, G.J. Levy and A.L. Mamedov. 2011. Superabsorbents and semiarid soil properties affecting water absorption. Soil Science Society of America Journal 75(6): 2305-2313.

Yu, J., J.G. Shi, X. Ma, P.F. Dang, Y.L. Yan, A.L. Mamedov, I. Shainberg and G.J. Levy. 2017. Superabsorbent polymer properties and concentration effects on water retention under drying conditions. Soil Science Society of America Journal 81(4): 889.

Zhou, B., R. Liao, Y. Li, T. Gu, P. Yang, J. Feng, W. Xing and Z. Zou. 2012. Water-absorption characteristics of organic-inorganic composite superabsorbent polymers and its effect on summer maize root growth. Journal of Applied Polymer Science 126(2): 423-435. 